\title{
BMJ Open Impact of the COVID-19 pandemic on anxiety and depression symptoms of young people in the global south: evidence from a four-country cohort study
}

\author{
Catherine Porter (D) , ${ }^{1}$ Marta Favara, ${ }^{2}$ Annina Hittmeyer, ${ }^{2}$ Douglas Scott, ${ }^{2}$ \\ Alan Sánchez Jiménez, ${ }^{3}$ Revathi Ellanki, ${ }^{4}$ Tassew Woldehanna, ${ }^{5}$ Le Thuc Duc, ${ }^{6}$ \\ Michelle G Craske, ${ }^{7}$ Alan Stein ${ }^{8,9}$
}

To cite: Porter C, Favara M, Hittmeyer A, et al. Impact of the COVID-19 pandemic on anxiety and depression symptoms of young people in the global south: evidence from a fourcountry cohort study. BMJ Open 2021;11:e049653. doi:10.1136/ bmjopen-2021-049653

- Prepublication history and additional supplemental material for this paper are available online. To view these files, please visit the journal online ().

Received 01 February 2021 Revised 18 March 2021 Accepted 23 March 2021

\section{Check for updates}

(C) Author(s) (or their employer(s)) 2021. Re-use permitted under CC BY. Published by BMJ.

For numbered affiliations see end of article.

\section{Correspondence to}

Dr Catherine Porter; catherine.porter@lancaster. ac.uk

\section{ABSTRACT}

Objective To provide evidence on the effect of the COVID-19 pandemic on the mental health of young people who grew up in poverty in low/middle-income countries (LMICs).

Design A phone survey administered between August and October 2020 to participants of a population-based Iongitudinal cohort study established in 2002 comprising two cohorts born in 1994-1995 and 2001-2002 in Ethiopia, India (Andhra Pradesh and Telangana), Peru and Vietnam. We use logistic regressions to examine associations between mental health and pandemic-related stressors, structural factors (gender, age), and lifelong protective/risk factors (parent and peer relationship, wealth, long-term health problems, past emotional problems, subjective well-being) measured at younger ages.

Setting A geographically diverse, poverty-focused sample, also reaching those without mobile phones or internet access

Participants 10496 individuals were approached; 9730 participated. Overall, 8988 individuals were included in this study; 4610 (51\%) men and 4378 (49\%) women. Noninclusion was due to non-location or missing data.

Main outcome measures Symptoms consistent with at least mild anxiety or depression were measured by Generalized Anxiety Disorder-7 ( $\geq 5$ ) or Patient Health Questionnaire-8 ( $\geq 5)$.

Results Rates of symptoms of at least mild anxiety (depression) were highest in Peru at $41 \%$ (32\%) $(95 \% \mathrm{Cl}$ $38.63 \%$ to $43.12 \%$; (29.49-33.74)), and lowest in Vietnam at $9 \%(9 \%)(95 \% \mathrm{Cl} 8.16 \%$ to $10.58 \%$; $(8.33-10.77))$, mirroring COVID-19 mortality rates. Women were most affected in all countries except Ethiopia. Pandemic-related stressors such as health risks/expenses, economic adversity, food insecurity, and educational or employment disruption were risk factors for anxiety and depression, though showed varying levels of importance across countries. Prior parent/ peer relationships were protective factors, while long-term health or emotional problems were risk factors.

Conclusion Pandemic-related health, economic and social stress present significant risks to the mental health of young people in LMICs where mental health support is limited, but urgently needed to prevent long-term consequences.
Strengths and limitations of this study

- The study uses data from adolescents and young adults who grew up in poverty in four low/middleincome countries which were diversely affected by the COVID-19 pandemic, therefore investigating a globally vulnerable but understudied group both in terms of age and wealth.

- This study reaches a broad sample of young people who grew up in poverty, including those without internet or direct access to a mobile phone.

- A key strength is combining a broad range of pandemic-related stressors from survey data on experiences of COVID-19 with previously measured information on longer term risk and protective factors, therefore contributing to a more complete picture of COVID-19 effects.

- A limitation of the study is that it does not have a directly comparable pre-COVID-19 baseline for depression/anxiety, however, proxy variables are used as a baseline and the explanatory variables capture dynamics that happened during the pandemic.

- A further limitation is possible under-reporting due to stigma associated with mental health, despite piloting and validation, as well as possible bias in selfreported experiences of pandemic-related stressors due to feelings of anxiety or depression.

\section{INTRODUCTION}

The COVID-19 pandemic is creating concerns about the mental health of young people around the globe. There has been a call for research funders and researchers to 'deploy resources to understand the psychological effects' ${ }^{\prime}$ of the COVID-19 pandemic and the ensuing 'mental health crisis'. ${ }^{2}$ The crisis likely exacerbates previous risk factors of poverty and vulnerability. The Lancet Commission on Global Mental Health had already identified poverty as a key risk factor for the onset and persistence of mental disorders. ${ }^{3}$ A recent study ${ }^{4}$ found that those with 
the lowest income were much more likely to suffer from anxiety and depressive disorders than their wealthier counterparts and points to the bidirectional causal relationship between poverty and mental health.

Several studies have examined the mental health impacts of the pandemic, predominantly in high-income countries. ${ }^{5-7}$ The few studies from low/middle-income countries (LMICs) have primarily relied on convenience samples and internet-based surveys, ${ }^{8-11}$ which are unlikely to reach the rural poor, though one study ${ }^{12}$ investigated the effect of immediate lockdown orders on (adult) women's mental health and experiences of intimate partner violence using a phone survey in rural Bangladesh.

Half of all mental health conditions develop by 14 years of age and $75 \%$ by early adulthood. ${ }^{3}$ In developed countries, young women aged 16-24 years are the most likely to have experienced a deterioration in mental health during the pandemic. ${ }^{13}$ Thus, understanding risk and protective factors during the pandemic at this age is critical to prevention, especially for the poorest. There is little research on the mental health of adolescents in LMICs, though they make up the bulk of the global adolescent population. ${ }^{14}$

This study examines the impact of the COVID-19 pandemic on the mental health of nearly 10000 young people from a 20-year cohort study operating in four LMICs: Ethiopia, India (Andhra Pradesh and Telangana), Peru and Vietnam. When the cohorts were originally recruited, the objective was to ensure that families living in poverty were substantially represented. ${ }^{15-18}$ Nowadays, these countries represent a diverse set of experiences during the pandemic, in terms of number and severity of cases, as well as policy responses. Figure 1 shows that COVID-19 has had by far the most striking impact in Peru in terms of deaths per population, followed by India. In

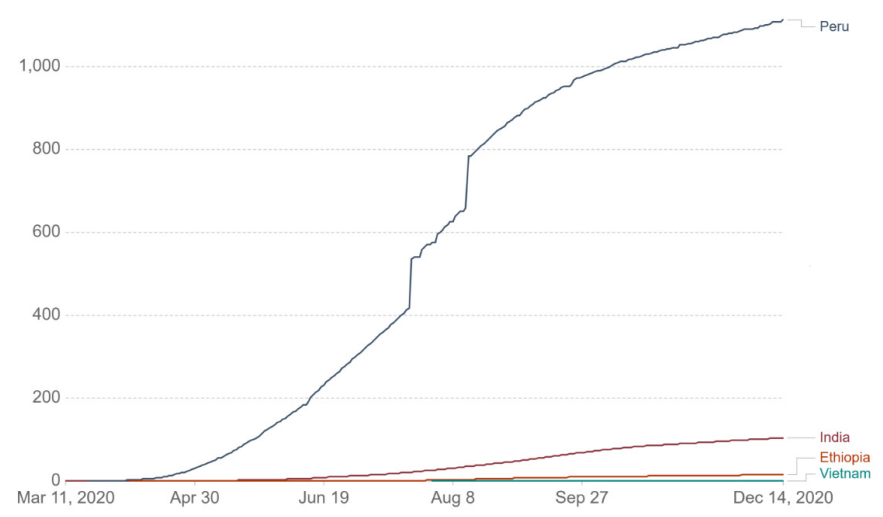

Figure 1 Cumulative confirmed COVID-19 cases per million people in the four Young Lives countries. Source: Johns Hopkins University CSSE COVID-19 Data, ${ }^{71}$ accessed via our world in data. ${ }^{59}$ Last updated 15 December 2020. Testing and challenges in the attribution of the cause of death mean that the number of confirmed deaths may not be an accurate count of the true number of deaths from COVID-19. CSSE, Center for Systems Science and Engineering

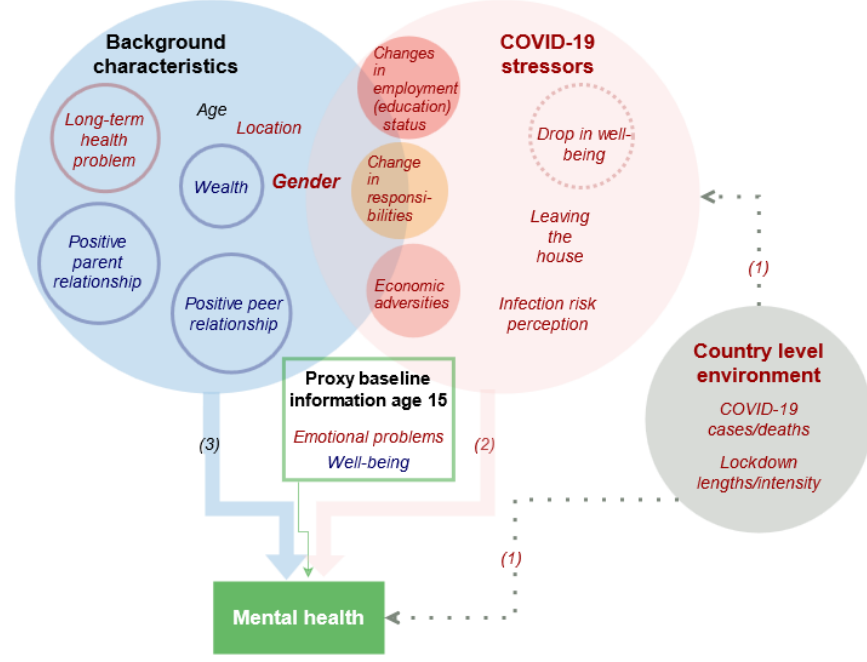

Figure 2 Theoretical framework of the hypothesised impact of COVID-19 stressors, background characteristics and the country-level environment on mental health. (1), (2) and (3) are the channels as discussed in the framework. Red font colour indicates hypothesised risk factors, blue font colour hypothesised protective factors. In case of gender, women are the hypothesised vulnerable group. Urban participants are hypothesised to be more vulnerable than rural residents (location). Black font colour indicates a potential effect in either direction. White font colour refers to outcome variables. (Solid) lines indicate that the variable was measured in previous in-person rounds. Filled subcircles are categorical/ composite variables. Boxes with no fill colour indicate robustness checks to the main framework. Dotted arrows indicate that the variable was only considered implicitly for descriptive statistics. Solid arrows indicate use in logistic regressions. Changes in employment status and changes in the educational status (=educational disruption) are used interchangeably for the younger cohort. Mental health was measured using the GAD-7 and PHQ-8 and a cut-off of five reflecting at least mild symptoms of anxiety/depression was chosen. GAD-7, Generalized Anxiety Disorder-7; PHQ-8, Patient Health Questionnaire-8.

contrast, Vietnam has been hailed as a success story in controlling the spread of the virus.

Our structural framework is a set of three hypothesised channels through which the pandemic may affect mental health, which are illustrated in figure 2 . The first is the country-level environment. Pressure on mental health is likely to be greater in countries which are more affected by the pandemic. Second, within each country, stressors related to changes in circumstances/behaviours/wellbeing that occurred due to the pandemic are hypothesised to negatively affect mental health,${ }^{1920}$ which we term as COVID-19-related stressors. These include individuals' perceived infection risk, economic adversities, changes in employment status and increased household responsibilities, educational disruption, and changes in subjective well-being (SWB) between 2016 and the pandemic. Third, we consider individual, household, and contextual background characteristics which may be protective and/ or interact negatively with pandemic-related stressors. 
We hypothesised that residents of urban areas may have difficulties social distancing in slum-like conditions and are possibly more likely than residents in rural areas to develop mental health conditions. Similarly, depression and anxiety symptoms have been shown to increase more among women than men in other countries. ${ }^{521}$ Changes imposed by COVID-19 in time use, ${ }^{22}$ education and work may also impact the genders differently. ${ }^{23}{ }^{24}$ Further, we exploited information collected in previous survey rounds to investigate characteristics measured during childhood and adolescence: positive social interactions (parent and peer relations), household wealth and long-term health conditions. We also include proxy baseline information for mental health in the form of past emotional problems and SWB measured 10 years ago at age 15 years. Our data and methods allow us to discuss the first hypothesis and to directly test the second and third hypotheses.

\section{METHODS}

\section{Study design and participants}

A phone survey ${ }^{25-28}$ (see online supplemental documents) was administered between August and October 2020 as part of the Young Lives Study, ${ }^{29}$ a longitudinal survey established in 2002 following two cohorts of children born in 1994-1995 and 2000-2001 in Ethiopia, India (Andhra Pradesh and Telangana), Peru and Vietnam. The choice to focus on these four countries was made by the original study team in 2001. The Young Lives Study was designed to monitor the effectiveness of the Millennium Development Goals (2000-2015) in reducing childhood poverty in varied political-economic and sociocultural settings. This led to the selection of four study countries, reflecting a diverse set of geography and development stages ${ }^{29}$.

Respondents have been surveyed in person every 3 years, with five consecutive rounds completed by 2016. In 2020, the cohort members are aged 18-19 (younger cohort) and 25-26 years (older cohort). The original sample was selected to include a significant coverage of poorer areas. ${ }^{15-18}$ Ninetythree per cent of the cohort (9704) were tracked in 2019. The sample was reduced to 8988 individuals due to missing values for any question (online supplemental tables 1 and 2) including between $0.1 \%$ (Vietnam) and 2\% (Peru) who did not respond to the mental health questions (online supplemental table 3).

The phone survey was administered over mobile telephone by up to 15 trained interviewers per country, who were provided with the hardware, software and internet access required for working from home. In Ethiopia, roughly $51 \%$ of participants did not have access to the internet via a working smartphone or a home computer. Thus, we used local guides who provided sanitised mobile phones for those who did not have them. Responses were recorded in an electronic questionnaire using Surveybe Implementer software.

Symptoms of anxiety and depression were measured using the Generalized Anxiety Disorder-7 (GAD-7) scale and the Patient Health Questionnaire depression scale-8
(PHQ-8). The GAD-7 has been validated ${ }^{30}$ and used in all four study countries. ${ }^{31-36}$ The PHQ-9 was also validated $^{37-41}$ and used in several studies. ${ }^{33-36} 42-47$ The ninth question of PHQ was dropped due to ethical concerns about how to provide support. The scales were slightly adapted for administration in a phone survey. First, we asked participants whether they were alone in the room and if not, whether they could find a quiet space and/ or make sure their phone speaker was off. Second, for each item in GAD-7 and PHQ-8, we asked whether the symptom had been observed (Yes/No) over the past 14 days, and if 'Yes' we then asked about the frequency. The scales were administered as the last section of the survey.

GAD-7 scores between 5 and 9, 10 and 14 and above 15 represent mild, moderate and severe anxiety, respectively. ${ }^{48}$ A PHQ-8 score between 5 and 9, 10 and 14, 15 and 19 and above 19 was considered representative of mild, moderate, moderately severe and severe depression, respectively. ${ }^{49}$ Cronbach's alpha ${ }^{50}$ for both scales was close to or above $0.7 .^{51}$ Interitem correlations fell within the recommended range $\left(0.15-0.50^{52} 53\right.$; online supplemental table 4).

\section{Statistical analysis}

In table 1 we present t-tests to show differences between groups (eg, male/female, urban/rural). Logistic regressions were used to examine the relationship between a range of stressors on a binary variable indicating (at least) mild anxiety (GAD-7 $\geq 5$ ) and (at least) mild depression (PHQ-8 $\geq 5$ ), as reported in the Results section. We include two sets of stressors hypothesised to be associated with mental health: changes in circumstances/behaviours/ well-being that occurred due to the pandemic (COVID19-related stressors) and, background characteristics that might act as risk or protective factors. We also include proxy baseline information (emotional problems and SWB measured 10 years earlier). The characteristics of the sample population are shown in online supplemental table 5. Online supplemental figure 1 gives an overview of the variables used in the analysis and the respective ages when they were measured.

The first set of COVID-19-related stressors include perceived COVID-19 infection risk, the extent to which people practise self-isolation (having left the house in the past 7 days), increased household responsibilities (including spending more time caring for children, on household chores or working in a family business), suffering from any adverse economic events (including increases in the price of food, incurring increased health expenditures, fewer clients in a family business, and if so, whether the household reduced food consumption to cope with it) and changes in working status compared with before the pandemic. In further analysis, for the 19-year-old cohort, we replaced working status with engagement with education, given that more than half of this group were still enrolled when the pandemic began (online supplemental tables 6 and 7). Finally, among the COVID-19-related stressors, we included the change in SWB 


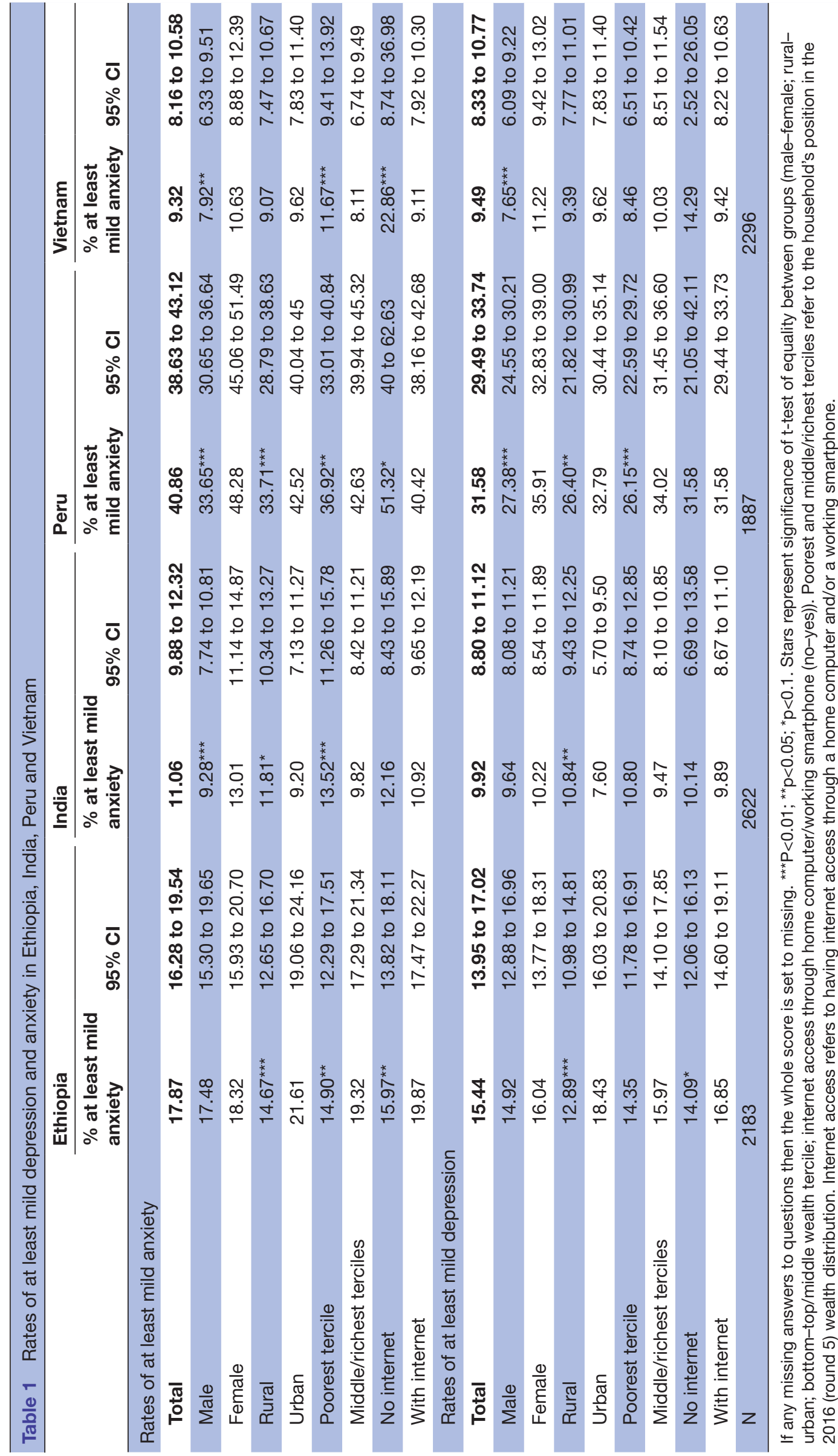


between 2016 and the pandemic. SWB was measured in round 5 (2016) at ages 15 and 22 years, and in the phone survey. Cantril's Ladder ${ }^{54}$ asks respondents to visualise a ladder of nine steps; the bottom (top) step representing their worst (best) possible life. Respondents are asked to identify which step they presently stand on. The difference in SWB is a continuous variable ranging from -8 to +8 .

The second set of background characteristics include individual-level and household-level risk and protective factors: gender, age, location, as well as long-term health problems and past household wealth, ${ }^{55}$ both measured in 2016, and parent-child and peer-child relationships, measured using the total raw scores of the Marsh SelfDescription Questionnaires $\mathrm{II}^{56}$ and $\mathrm{I} .{ }^{57}$ Both scores range between 8 and 32, with higher scores representing more positive relationships. Peer relationships were obtained at ages 15 (younger cohort) and 22 years (older cohort) in 2016. Parent relationships were obtained at ages 15 (younger cohort, 2016) and 19 years (older cohort, 2013).

GAD-7 and PHQ-8 were not measured in previous survey rounds. Therefore, we control for proxy baseline information including emotional problems and SWB, both available for the 25-year-old cohort only in 2009 (round 3 ) at the age of 15 years (online supplemental tables 8 and 9). The Emotional Problem Scale comes from the self-completed Strengths and Difficulties Questionnaire. Total scores range from 0 to 10 , a higher score indicates more severe emotional problems. We report extensive disaggregated rates of mental health issues (online supplemental tables 10-15).

Changes in responsibilities, the labour market and education environment may affect men and women differently. Therefore, we re-estimated the regressions separately by gender (online supplemental tables 16-23). We report ORs, robust SEs and the 95\% CIs for all regressions.

\section{Patient and public involvement}

No patients or the public were involved in the study design, setting the research questions, interpretation or writing up of results, or reporting of the research as it is a prospective cohort study.

\section{RESULTS}

Across the four countries, 93\% of the Young Lives sample, who were located during the last tracking exercise in November 2019, participated in the phone survey. Only between $0.1 \%$ (Vietnam) and 2\% (Peru) did not respond to the mental health questions. The results presented in this section refer to the participants aged 19 years and 25 years together, unless differently specified.

\section{Country comparisons}

Both mild anxiety (41\%, 95\% CI $38.63 \%$ to $43.12 \%)$ and mild depression (32\%, 95\% CI $29.49 \%$ to $33.74 \%$ ) rates were highest in Peru, followed by Ethiopia (anxiety:
$18 \%, 95 \%$ CI $16.28 \%$ to $19.54 \%$; depression: $15 \%$, $95 \%$ CI $13.95 \%$ to $17.02 \%$ ) (see table 1 ). The rates of moderate/severe anxiety and depression were highest in Peru, $13.5 \%$ (95\% CI $12.00 \%$ to $15.14 \%$ ) and $9.6 \%$ (95\% CI $8.35 \%$ to $11.07 \%$ ), and below $3 \%$ in the other countries (online supplemental tables 24-31). Women had significantly higher rates of anxiety symptoms in all countries except Ethiopia and higher rates of depression in Peru and Vietnam. In Peru, almost half of all women had symptoms consistent with at least mild anxiety. Rates of anxiety and depression in rural areas were significantly lower than urban rates in Ethiopia and Peru, but significantly higher in India. The poorest wealth tercile had significantly lower rates of anxiety in Ethiopia and Peru, but higher rates in India and Vietnam. In Peru, the poorest wealth tercile also had significantly lower rates of depression. Those not having any access to the internet, although a minority, had significantly higher levels of anxiety (Vietnam $\mathrm{p}<0.01$, Peru $\mathrm{p}<0.1$ ).

We note a high correlation between GAD-7 and PHQ-8 scores (minimum $0.610(\mathrm{p}<0.01)$ (India) and maximum $0.700(\mathrm{p}<0.01)($ Peru $)$ ), and the rate of having both (at least mild) anxiety and depression symptoms was high, with values of up to $24.8 \%$ (95\% CI $22.87 \%$ to $26.81 \%$ ) in Peru (online supplemental tables 32 and 33). We use Pearson's correlation coefficient with Bonferroni corrected $\mathrm{p}$ values to investigate (1) the relationship between GAD-7 and PHQ-8 raw scores and (2) the relationship between SWB and GAD-7 and PHQ-8 raw scores.

The significant risk and protective factors were similar. For brevity, the main results refer to associations with experiencing at least mild anxiety symptoms (see table 2 ), pooling the two cohorts and women and men together (unless differently specified). At the end, we comment on the differences between these results and those for depression (see table 3).

\section{Logistic regression results (0Rs): at least mild anxiety COVID-19-related stressors}

COVID-19 infection risk perception: The odds of those who believed that they were at medium/high risk of catching the virus were 1.27 (95\% CI 0.98 to $1.63, \mathrm{p}<0.1)$ (India) to 1.46 (95\% CI 1.20 to $1.78, \mathrm{p}<0.01$ ) (Peru) times higher than for those who believed themselves to have no/low risk. The former group had rates of at least mild anxiety of $12 \%$ (India) and $45 \%$ (Peru).

Leaving the house for at least 1 day a week: No significant effects, except in India where it increased the odds of anxiety by 1.40 ( $95 \%$ CI 0.96 to $2.06, \mathrm{p}<0.1)$.

Economic adversity: For those who suffered from economic adversity (eg, fewer clients in the family business, food price increase), odds of anxiety were higher ( $\mathrm{p}<0.01$ (Ethiopia and Vietnam), (2.50, 95\% CI 1.14 to $5.46, \mathrm{p}<0.05)(2.40,95 \%$ CI 1.01 to 5.72, $\mathrm{p}<0.05)($ Peru $))$ even if it did not cause reduced food consumption. Moreover, in Ethiopia and Vietnam, those who reduced food consumption as a coping strategy had $7.19(95 \%$ CI 4.51 to $11.45, \mathrm{p}<0.01)$ (Ethiopia) and 1.67 (95\% CI 


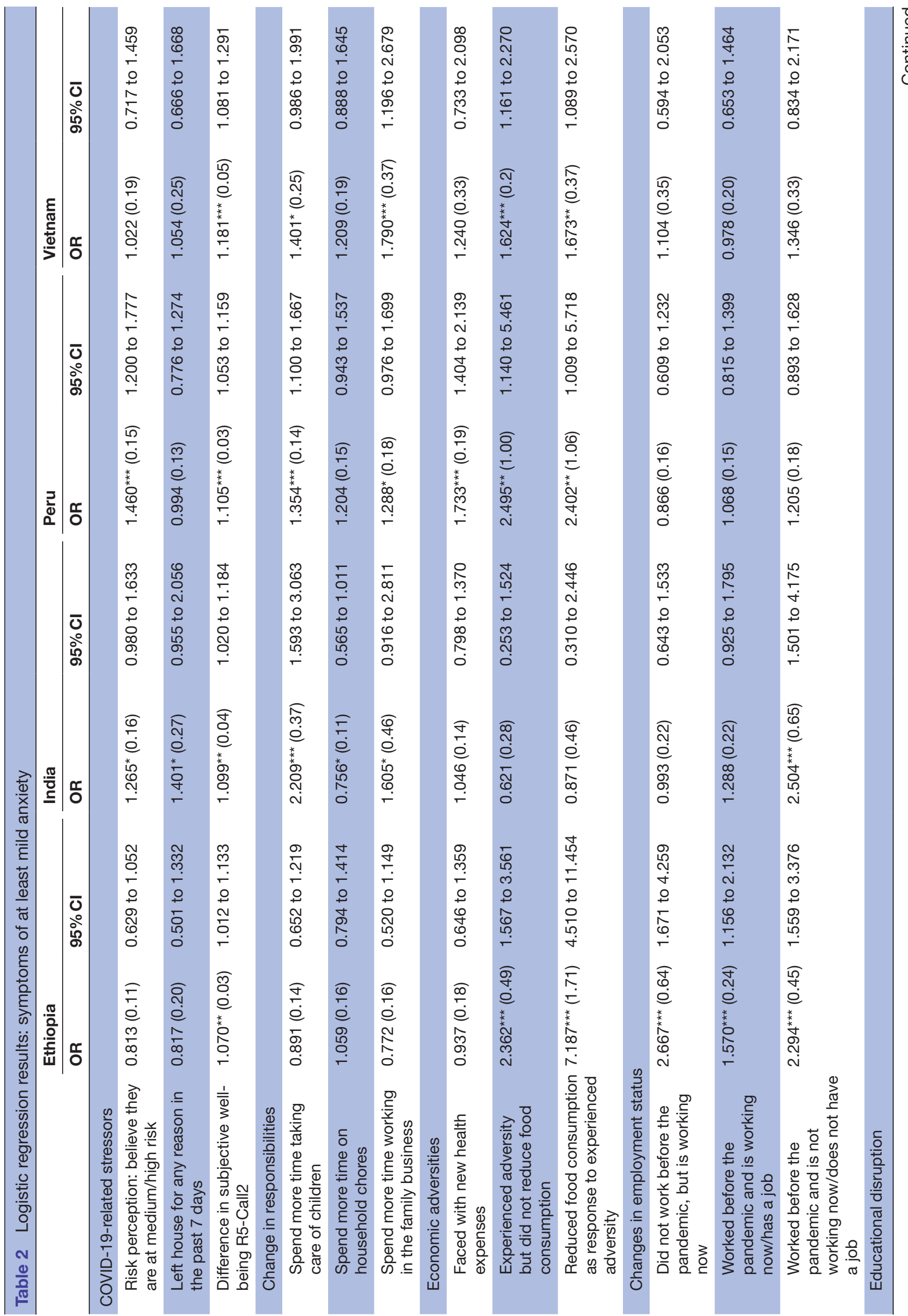




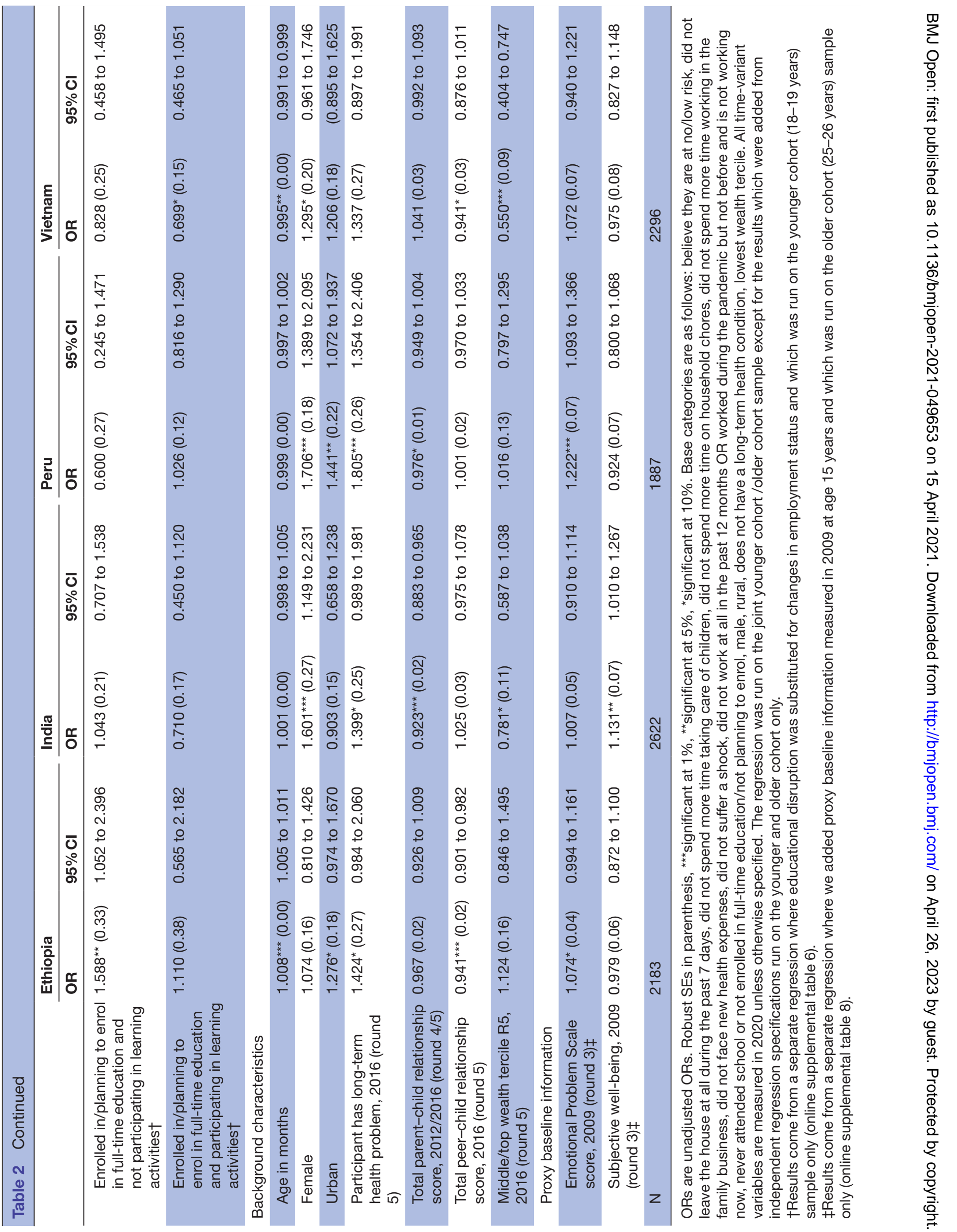




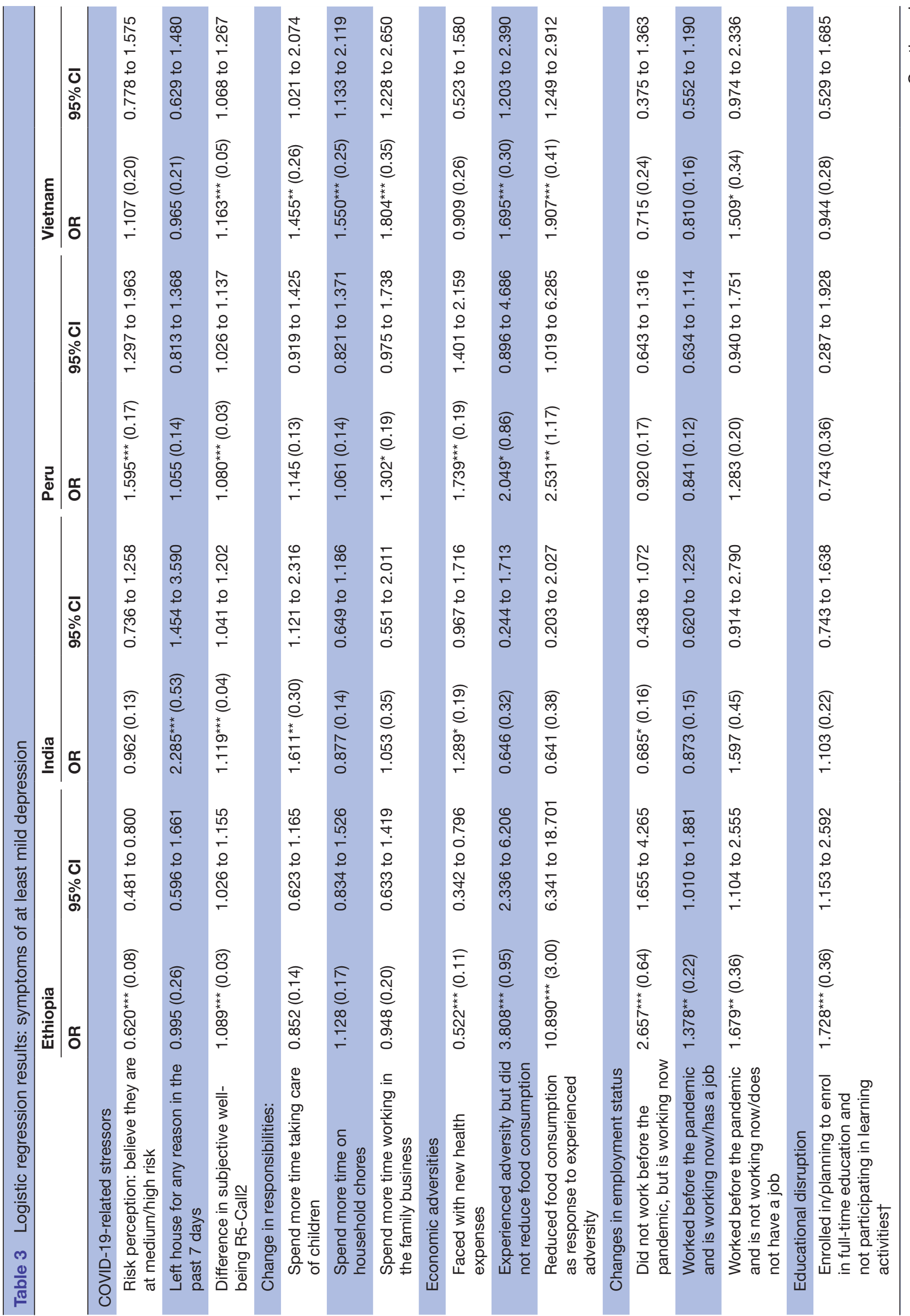




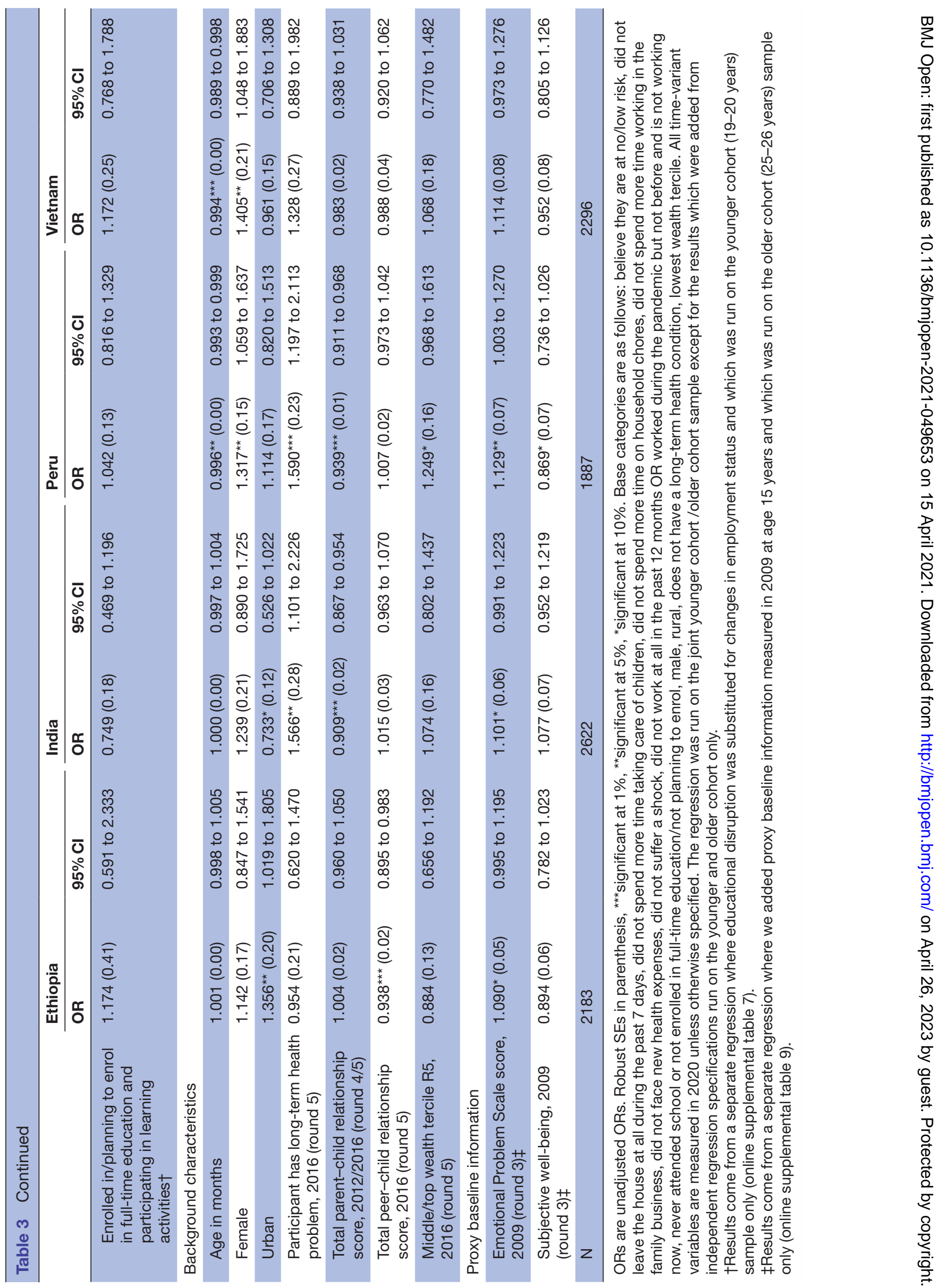


1.09 to $2.57, \mathrm{p}<0.05)$ (Vietnam) higher odds than those who experienced an adverse event but did not need to reduce food consumption in response 2.36 (95\% CI 1.57 to $3.56, \mathrm{p}<0.01)$ (Ethiopia) and 1.62 (95\% CI 1.16 to 2.27, $\mathrm{p}<0.01$ ) (Vietnam) (both compared with those who did not experience any adverse event at all). In Ethiopia, $36 \%$ of those who reduced food consumption reported at least mild anxiety compared with $7 \%$ of those who did not experience an adverse event $(\mathrm{p}<0.0001)$. In Ethiopia, odds were higher among women than men, but in Peru and Vietnam significant for men only. Facing new health expenses significantly increased the odds by 1.73 (95\% CI 1.40 to 2.14$)(\mathrm{p}<0.01)$ in Peru. Over half $(52 \%, \mathrm{p}<0.0001)$ of those who faced new health expenses report at least mild anxiety (although not significant in India or Ethiopia, significant risk factor for women in Vietnam (1.76, $95 \%$ CI 0.93 to $3.31, \mathrm{p}<0.1)$ ).

\section{Increased responsibilities}

Spending more time on childcare during the lockdown increased odds of anxiety by 2.21 (95\% CI 1.59 to 3.06 , $\mathrm{p}<0.01$ ) in India, 1.35 (95\% CI 1.10 to $1.67, \mathrm{p}<0.01$ ) in Peru and 1.4 (95\% CI 0.99 to $1.99, \mathrm{p}<0.1)$ in Vietnam. Rates for those who spent more time taking care of children were $20 \%$ vs $9 \%$ (India), $49 \%$ vs $37 \%$ (Peru) and $13 \%$ vs $8 \%$ (Vietnam), (all $\mathrm{p}<0.001)$. Spending more time on household chores lowered odds in India for anxiety (women only). For those who spend more time working in the family business, the odds of anxiety were 1.61 (95\% CI 0.92 to $2.81, \mathrm{p}<0.1)$ times higher in India, $1.29(95 \%$ CI 0.98 to $1.67, \mathrm{p}<0.1$, n.s. for women) in Peru and 1.80 (95\% CI 1.20 to $2.68, \mathrm{p}<0.01$ ) in Vietnam (higher odds among men). In Vietnam, those who spent more time working in the family business reported rates of $16 \%$ $(p<0.0001)$, the highest among the Vietnamese sample.

\section{Changes in employment status}

In Ethiopia, those who participated in the labour market had higher odds of anxiety than those who did not (eg, full-time students, stay-at-home parents). However, the odds of those who were pushed into the labour market $(2.67,95 \%$ CI 1.67 to $4.26, \mathrm{p}<0.01)$ or lost their job (2.29, $95 \%$ CI 1.56 to $3.38, \mathrm{p}<0.01$ ) were higher than those who simply participated $(1.57,95 \%$ CI 1.16 to $2.13, \mathrm{p}<0.01)$ (all in comparison with non-participants). In India, losing a job increased the risk of anxiety by 2.50 (95\% CI 1.50 to $4.18, \mathrm{p}<0.01)$. In Peru and Vietnam, there were no employment effects. Rates of at least mild anxiety among those who lost their jobs were among the highest in each country $31 \%$ (Ethiopia, $\mathrm{p}<0.001$ ), $20 \%$ (India, $\mathrm{p}<0.001$ ), $46 \%$ (Peru, n.s.), 12\% (Vietnam, n.s.).

\section{Educational disruption (19-year-old cohort only)}

Students who were enrolled in Ethiopia before the pandemic and were unable to access virtual classes or complete homework had 1.59 (95\% CI 1.05 to 2.40, $\mathrm{p}<0.05)$ times higher odds of anxiety than those who were not enrolled. In Vietnam, those who were enrolled and engaged in learning activities had lower odds of anxiety $(0.70,95 \%$ CI 0.47 to $1.05, \mathrm{p}<0.1)$ than those who were not enrolled (base category). The full younger cohort only regression results can be found in online supplemental table 6 ; the education results split by gender (again younger cohort only) are located in online supplemental tables 20-23.

\section{Background characteristics}

For women, the odds were 1.30 (95\% CI 0.96 to 1.75 , $\mathrm{p}<0.1$ ) (Vietnam), 1.60 (95\% CI 1.15 to $2.23, \mathrm{p}<0.01$ ) (India) and 1.70 (95\% CI 1.39 to $2.10, \mathrm{p}<0.01)$ (Peru) times greater than the odds for men (n.s. in Ethiopia). Urban location increased odds significantly in Ethiopia and Peru. Age was not significant in India and Peru, protective in Vietnam and a risk factor in Ethiopia.

Long-term health problems (measured in 2016): the odds of at least mild anxiety were 1.42 (95\% CI 0.98 to 2.06, $\mathrm{p}<0.1$ ) (Ethiopia), 1.40 (95\% CI 1.00 to $2.00, \mathrm{p}<0.1$ ) (India) and 1.80 (95\% CI 1.35 to $2.41, \mathrm{p}<0.01)$ (Peru) times as large as the odds for those who did not (n.s. in Vietnam). In Peru, those reporting long-term health problems had the highest rates of at least mild anxiety, $56 \%(\mathrm{p}<0.0001)$.

Parent-child relationship (measured at age 15 years for the younger cohort, in 2016 and measured at age 19 years for the older cohort, in 2013) and peer-child relationship (at age 15 years for the younger cohort and at age 22 years for the older cohort, in 2016): strong parent-child relationships were a significant protective factor in India and Peru, while peer-child relationships were a significant protective factor in Ethiopia and Vietnam.

Past household wealth (measured in 2016): that is, being in the middle/highest wealth tercile versus the lowest was a marginally significant protective factor in India $(0.78$, $95 \%$ CI 0.59 to $1.04, \mathrm{p}<0.1)$ and significant in Vietnam $(0.55,95 \%$ CI 0.40 to $0.75, \mathrm{p}<0.01)$.

\section{Proxy baseline information}

Past emotional problems and well-being (25-year-old cohort only): for a one-point increase in previous emotional problems at age 15 years (measured in 2009), the odds of at least mild anxiety increased by a factor of $1.22(95 \%$ CI 1.09 to $1.37, \mathrm{p}<0.01$ ) (Peru) and 1.07 (95\% CI 0.99 to $1.16, \mathrm{p}<0.1)$ (Ethiopia). Notably, the effect of the COVID19-related stressors holds when controlling for past proxy baseline information. The full older cohort only regression results can be found in online supplemental table 8 .

\section{Significant differences between anxiety and depression logistic regression results}

As previously mentioned, the results for anxiety and depression (see table 3 and online supplemental tables $7,9,16-23,34-36)$ are qualitatively similar. Here we note significant differences in the results between the two independent variables for each country. In Ethiopia, food insecurity had a higher impact on depression for men than women. In India, subjective high infection risk 
increased anxiety, but not depression, and those faced with new health expenses had higher odds of depression, but not anxiety. Women also had higher rates of anxiety but not depression. In Peru, childcare was not a risk factor for depression, and past SWB was a protective factor. In Vietnam, losing a job was a significant risk factor for depression, while good peer relations and education were not significant determinants of depression.

\section{DISCUSSION}

We examined the impact of the COVID-19 pandemic on the mental health of young people in Ethiopia, India, Peru and Vietnam. The sample has broad coverage of the poorer population in each country, and we interviewed 93\% of those located during the tracking prior to the pandemic, including those without internet access and in Ethiopia also those without mobile phone, who would be excluded from an online survey. Internet access has had both positive and negative effects in the pandemic. ${ }^{58}$ In our sample, those without access to internet have significantly higher rates of anxiety in Vietnam and Peru.

The four countries have had different experiences of the pandemic-Peru is the most affected country in terms of deaths per population, and Vietnam the least. While Vietnam has recorded only 35 deaths in total (not per day), with no deaths since 3 September 2020, on 15 October (end date of our survey) Peru had registered 33577 deaths. ${ }^{59}$ Another aspect which has likely contributed to the difference is the length of the lockdown, which creates stress and reduces household income. In Peru, this was 107 consecutive days at the national level, followed by an additional period of local lockdowns, such that certain areas of the country were in lockdown for up to 199 days. In contrast, Vietnam had a very short and successful lockdown, one further localised lockdown, but by September life was already back to normal. Ethiopia restricted certain activities and closed schools, but did not impose a strict lockdown, though faced other challenges (locust infestations, food price inflation and violence).

This study reveals a strong relationship between the severity of the pandemic and the rates of mental health conditions in our sample, both in terms of anxiety and depression symptoms. Rates of at least mild anxiety (depression) were four (three) times higher in Peru compared with Vietnam. Furthermore, the 2020 survey showed a significant fall in SWB from 2016 in all countries except Vietnam. The fall in SWB is highly correlated with anxiety and depression symptoms. In the absence of baseline measures of GAD-7 and PHQ-8, a strong correlation between SWB and our mental health indicators is important, as it suggests that SWB is a useful proxy baseline.

The economic impact of the pandemic has affected certain groups of young people in all study countries, even Vietnam, and Ethiopia where there was no full national lockdown. Overall, our findings confirmed that those experiencing COVID-19-related stressors had worse mental health, although the relative importance of stressors varied across countries: increased health expenses and believing they were at a medium/high infection risk was detrimental for young people in Peru, but increased food insecurity was much more important in Ethiopia, reflecting high rates of food price inflation in 2019, which continued into 2020. Moreover, good peer relations in earlier years were a protective factor for anxiety and depression only in Ethiopia. In Peru and Vietnam, there were no employment effects on anxiety, likely for very different reasons-in Peru health concerns were more important, and in Vietnam, the labour market was relatively resilient.

Exploiting the longitudinal data allowed us to investigate individual-level and household-level protective and risk factors. As expected, parent and peer relations measured during childhood and adolescence were protective, though in different ways across countries. Strong parental relationships were a significant protective factor in India and Peru, whereas peer relationships were more important in Ethiopia and Vietnam. Those reporting long-term health problems were twice as likely to display symptoms consistent with at least mild anxiety, this effect being particularly pronounced in Peru. Previous relative wealth was a significant protective factor only in India and Vietnam. Pre-pandemic emotional problems were risk factors, especially in Ethiopia and Peru. The associations with COVID-19-related stressors were robust to the inclusion of pre-pandemic emotional problems and past SWB.

Other studies have used longitudinal data to document the impact of the pandemic on mental health, ${ }^{5}{ }^{12}$ though none investigate a comparable population of young people, of a similar age, with those in our study countries, though results from the UK have similar findings. The closest study to ours, a phone survey in a developing country, finds a deterioration in maternal mental health in rural Bangladesh. ${ }^{12}$ Our study shows lower rates of anxiety and depression in rural areas in Ethiopia and Peru, but significantly higher in India. We are able to disaggregate the effect of a range of COVID-19-related stressors, which we can relate individually to other studies. A study in Hubei province, China ${ }^{11}$ showed the importance of income losses during the pandemic. Studies of college students in China ${ }^{8}$ and Bangladesh ${ }^{10}$ show that educational disruption significantly increased anxiety and depression, similar to our results in Vietnam and Ethiopia. Social support was negatively correlated with the level of anxiety, ${ }^{8}$ similar to our findings regarding parent/peer-child relationships. In Jordan, ${ }^{9}$ female healthcare professionals, female university students and university students with chronic disease were at higher risk of developing depression, similar to our results for long-term health problems.

Even controlling for other factors, we found women to be more vulnerable to anxiety in India, Peru and Vietnam and more vulnerable to depression in Peru and Vietnam. which is similar to most COVID-19-related $\mathrm{d}^{5911}$ and prepandemic studies. ${ }^{606}$ However, in Ethiopia, we found no 
significant gender effects. Previous studies in Ethiopia had mixed results on gender differences. ${ }^{62}{ }^{63}$ Relatedly, and during the COVID-19 pandemic, one ${ }^{8}$ study finds no gender differences among Chinese college students while another ${ }^{10}$ finds that male Bangladeshi students had higher depressive symptoms than women.

\section{Strengths and limitations}

This study's strength combines survey data about experiences of COVID-19 with long-term information from two cohorts of participants of a population-based cohort study in four LMICs. The study was able to cover the poorest, those without internet (and without mobile phone in Ethiopia), and examine the role of a broad range of pandemic-related stressors and of individuallevel and household-level risk and protective factors. Our study has a number of limitations. We do not have a directly comparable pre-COVID-19 baseline for depression/anxiety. However, we use proxy variables for baseline and our explanatory variables capture dynamics during the pandemic. As for other studies, there may be under-reporting in all four countries ${ }^{64-67}$ because of stigma associated with mental health, despite piloting and validation. There is evidence in the literature of stigmatisation of mental health in all four countries, as in other LMIC meta-analyses ${ }^{68}{ }^{69}$ but nothing to suggest this is associated with the differences we find. Furthermore, our analysis identifies high-risk groups within each country. Additionally, self-reported variables may be biased due to feelings of anxiety or depression. The findings are not fully generalisable to the whole population of LMICs due to the poverty-focused design and age group, however they broadly represent poor young people in the study countries.

\section{CONCLUSION}

Adolescents and young people have been a lower priority for COVID-19 interventions, given the lower rates of hospitalisation and death for this age group. This research shows that the pandemic is having important effects on the mental health of certain groups of young people, even in countries with fewer cases. Mental health services are very limited in LMICs, making it urgent to develop evidence-based and sustainable prevention programmes in response to the pandemic. As a short-term measure, funding for (and awareness of) telephone helplines can be increased, and Cash Transfer Programmes should be expanded or conditionality waived to cover young people hardest hit by the pandemic, and include mobile phone messaging to provide accurate non-stigmatised information about COVID-19 and available mental health support services. This could help break the cycle between poverty and mental illness, lowering the risk of long-term consequences. ${ }^{70}$ Further research on mental health in Peru (the country hardest hit by the pandemic among our four countries) should be conducted including estimating the impact on mental health resulting from lockdown length/intensity and COVID-19 cases/deaths on the district level.

\section{Author affiliations}

${ }^{1}$ Management School, Lancaster University, Lancaster, UK

${ }^{2}$ Oxford Department of International Development, University of Oxford, Oxford, UK

${ }^{3}$ Niños del Milenio, Grupo de Análisis para el Desarrollo (GRADE), Lima, Peru

${ }^{4}$ Director, Centre for Economic and Social Studies, Begumpet, India

${ }^{5}$ Department of Economics, Addis Ababa University, Addis Ababa, Ethiopia

${ }^{6}$ Centre for Analysis and Forecasting, Vietnam Academy of Social Sciences, Hanoi, Vietnam

${ }^{7}$ Department of Psychology, University of California Los Angeles, Los Angeles,

California, USA

${ }^{8}$ Department of Psychiatry, University of Oxford, Oxford, UK

${ }^{9}$ School of Public Health, University of the Witwatersrand, Johannesburg-

Braamfontein, South Africa

\section{Twitter Catherine Porter @EconCath}

Acknowledgements We particularly wish to thank the Young Lives respondents and their families for generously giving us their time and cooperation during this difficult time as well as fieldworkers and field managers in the four study countries. We are gratefully indebted to Professor George Patton for his helpful comments. Further, we would like to thank Professor Graham Thornicroft, Dr Julio Torales and Dr Gabriel Teck for their helpful feedback during the review process.

Contributors $\mathrm{CP}$ and MF conceived the study. CP, MF, DS and ASJ designed the study. MF, ASJ, RE, TW and LTD led data collection. CP and AH did the statistical analyses. $\mathrm{CP}, \mathrm{AH}$ and MF wrote the first draft of the article. AS and MC provided comments and input to the several drafts of the article. MF, DS and ASJ verified the underlying data. AS, MF, CP and $\mathrm{AH}$ assessed scale validation and methodology. $\mathrm{AH}$ prepared the supplemental files. All authors critically reviewed multiple versions of the manuscript and approved the final version.

Funding Young Lives at Work is funded by a UK aid from the Foreign, Commonwealth and Development Office (FCD0), under the Department for International Development, UK Government (grant number 200 425).

Disclaimer The funders of the study had no role in study design, data collection, data analysis, data interpretation or writing of the report. The views expressed are those of the authors. They are not necessarily those of, or endorsed by, the University of Oxford, Young Lives, FCDO. All authors had full access to the anonymised data in the study and had final responsibility for the decision to submit for publication.

Competing interests $\mathrm{CP}, \mathrm{MF}, \mathrm{AH}, \mathrm{DS}, \mathrm{ASJ}, \mathrm{RE}, \mathrm{TW}$ and LTD report grants from the FCDO, during the conduct of the study.

\section{Patient consent for publication Not required.}

Ethics approval The survey was approved by the institutional research ethics committees at the University of Oxford (UK), the University of Addis Ababa (Ethiopia), the Centre for Economic and Social Studies in Hyderabad (India), the Instituto de Investigación Nutricional (Peru) and the Hanoi University of Public Health (Vietnam). Participants were asked for their verbal informed consent before the study commenced and were assured of confidentiality. A consultation guide was provided to all participants with resources for support in issues raised by the questionnaire, including mental health. Approval number (0xford): CUREC 1A/ ODID CIA-20-034.

Provenance and peer review Not commissioned; externally peer reviewed.

Data availability statement Data are available in a public, open access repository. The entire individual participant data collected during the phone survey and previous in-person rounds, after de-identification, are available including data dictionaries. Furthermore, the questionnaire, attrition reports and the fieldwork manual are available at https://www.younglives.org.uk/. The data are available from January 2021, with no end date to anyone who wishes to access the data for any purpose, via the UK Data Archive (study number 8678, D0I: 10.5255/UKDASN-8678-1).

Supplemental material This content has been supplied by the author(s). It has not been vetted by BMJ Publishing Group Limited (BMJ) and may not have been peer-reviewed. Any opinions or recommendations discussed are solely those of the author(s) and are not endorsed by BMJ. BMJ disclaims all liability and responsibility arising from any reliance placed on the content. Where the content includes any translated material, BMJ does not warrant the accuracy and reliability 
of the translations (including but not limited to local regulations, clinical guidelines, terminology, drug names and drug dosages), and is not responsible for any error and/or omissions arising from translation and adaptation or otherwise.

Open access This is an open access article distributed in accordance with the Creative Commons Attribution 4.0 Unported (CC BY 4.0) license, which permits others to copy, redistribute, remix, transform and build upon this work for any purpose, provided the original work is properly cited, a link to the licence is given, and indication of whether changes were made. See: https://creativecommons.org/ licenses/by/4.0/.

ORCID iD

Catherine Porter http://orcid.org/0000-0002-8578-1744

\section{REFERENCES}

1 Holmes EA, O'Connor RC, Perry VH, et al. Multidisciplinary research priorities for the COVID-19 pandemic: a call for action for mental health science. Lancet Psychiatry 2020;7:547-60.

2 WHO. Substantial investment needed to avert mental health crisis, 2020. Available: https://www.who.int/news/item/14-05-2020substantial-investment-needed-to-avert-mental-health-crisis [Accessed 14 May 2020].

3 Patel V, Saxena S, Lund C, et al. The Lancet Commission on global mental health and sustainable development. The Lancet 2018;392:1553-98.

4 Ridley M, Rao G, Schilbach F, et al. Poverty, depression, and anxiety: causal evidence and mechanisms. Science 2020;370. doi:10.1126/ science.aay0214. [Epub ahead of print: 11 Dec 2020].

5 Pierce M, Hope H, Ford T, et al. Mental health before and during the COVID-19 pandemic: a longitudinal probability sample survey of the UK population. Lancet Psychiatry 2020;7:883-92.

6 Pan K-Y, Kok AAL, Eikelenboom M, et al. The mental health impact of the COVID-19 pandemic on people with and without depressive, anxiety, or obsessive-compulsive disorders: a longitudinal study of three Dutch case-control cohorts. Lancet Psychiatry 2021;8:121-9.

7 Czeisler Mark É, Lane RI, Petrosky E, et al. Mental Health, Substance Use, and Suicidal Ideation During the COVID-19 Pandemic United States, June 24-30, 2020. MMWR Morb Mortal Wkly Rep 2020;69:1049-57.

8 Cao W, Fang Z, Hou G, et al. The psychological impact of the COVID-19 epidemic on college students in China. Psychiatry Res 2020;287:112934.

9 Naser AY, Dahmash EZ, Al-Rousan R, et al. Mental health status of the general population, healthcare professionals, and university students during 2019 coronavirus disease outbreak in Jordan: a cross-sectional study. Brain Behav 2020;10:e01730.

10 Islam MA, Barna SD, Raihan $\mathrm{H}$, et al. Depression and anxiety among university students during the COVID-19 pandemic in Bangladesh: a web-based cross-sectional survey. PLoS One 2020;15:e0238162.

$11 \mathrm{Li} \mathrm{X,} \mathrm{Lu} \mathrm{P,} \mathrm{Hu} \mathrm{L,} \mathrm{et} \mathrm{al.} \mathrm{Factors} \mathrm{associated} \mathrm{with} \mathrm{mental} \mathrm{health} \mathrm{results}$ among workers with income losses exposed to COVID-19 in China. Int J Environ Res Public Health 2020;17. doi:10.3390/ijerph17155627. [Epub ahead of print: 04 Aug 2020].

12 Hamadani JD, Hasan MI, Baldi AJ, et al. Immediate impact of stayat-home orders to control COVID-19 transmission on socioeconomic conditions, food insecurity, mental health, and intimate partner violence in Bangladeshi women and their families: an interrupted time series. Lancet Glob Health 2020;8:e1380-9.

13 Banks J, Xu X. The mental health effects of the first two months of lockdown and social distancing during the Covid-19 pandemic in the UK. IFS Working Paper 2020.

14 Blum R, Boyden J. Understand young people in low-income countries. Nature 2018;544.

15 Escobal J, Flores E. An assessment of the young lives sampling approach in Peru. technical note. Young Lives: Oxford, 2008.

16 Kumra N. An assessment of the young lives sampling approach in Andhra Pradesh, India. technical note. Young Lives: Oxford, 2008.

17 Nguyen NP. An assessment of the young lives sampling approach in Vietnam. technical note. Young Lives: Oxford, 2008.

18 Outes-Leon I, Sanchez A. An assessment of the young lives sampling approach in Ethiopia. technical note. Young Lives: Oxford, 2008.

19 Ling GHT, Md Suhud NAB, Leng PC, et al. Factors influencing AsiaPacific countries' success level in Curbing COVID-19: a review using a Social-Ecological system (Ses) framework. Int J Environ Res Public Health 2021;18. doi:10.3390/ijerph18041704. [Epub ahead of print: 10 Feb 2021]

20 Al Omari O, Al Sabei S, Al Rawajfah O, et al. Prevalence and predictors of depression, anxiety, and stress among youth at the time of COVID-19: an online cross-sectional multicountry study. Depress Res Treat 2020;2020:8887727.

21 Khademian F, Delavari S, Koohjani Z, et al. An investigation of depression, anxiety, and stress and its relating factors during COVID-19 pandemic in Iran. BMC Public Health 2021;21:275.

22 Favara M, Freund R, Porter C. Young lives, interrupted: short-term effects of the COVID-19 pandemic on adolescents in low- and middle-income countries. Covid Economics 2021;67:172-98.

23 Burki T. The indirect impact of COVID-19 on women. Lancet Infect Dis 2020;20:904-5.

24 Reichelt M, Makovi K, Sargsyan A. The impact of COVID-19 on gender inequality in the labor market and gender-role attitudes. European Societies 2021;23:S228-45.

25 Scott D, Thuc DL, Hittmeyer A. Listening to Young Lives at Work in Vietnam: Second Call. In: Listening to young lives at work phone survey, 2020: 2.4. https://www.younglives.org.uk/sites/www. younglives.org.uk/files/YOL-Vietnam-Headlines-PhoneSurvey2Nov20.pdf

26 Porter C, Woldehanna T, Freund R. Listening to Young Lives at Work in Ethiopia: Second Call. In: Listening to young lives at work phone survey, 2020: 2.1. https://www.younglives.org.uk/sites/www. younglives.org.uk/files/YOL-Ethiopia-Headlines-PhoneSurvey2Nov20.pdf

27 Favara M, Ellanki R, MdIÁ M. Listening to Young Lives at Work in Andhra Pradesh and Telangana: Second Call. In: Listening to young lives at work phone survey, 2020: 2.2. https://www.younglives. org.uk/sites/www.younglives.org.uk/files/YOL-India-HeadlinesPhoneSurvey2-Nov20.pdf

28 Sánchez A, Cueto S, Mary Penny JL. Listening to Young Lives at Work in Peru: Second Call. In: Listening to young lives at work phone survey, 2020: 2.3. https://www.younglives.org.uk/sites/www. younglives.org.uk/files/YOL-Peru-Headlines-PhoneSurvey2-Nov202\%2023rd\%20.pdf

29 Barnett I, Ariana P, Petrou S, et al. Cohort profile: the young lives study. Int J Epidemiol 2013;42:701-8.

30 Zhong Q-Y, Gelaye B, Zaslavsky AM, et al. Diagnostic Validity of the Generalized Anxiety Disorder - 7 (GAD-7) among Pregnant Women. PLoS One 2015;10:e0125096.

31 Gezie LD, Yalew AW, Gete YK, et al. Socio-economic, trafficking exposures and mental health symptoms of human trafficking returnees in Ethiopia: using a generalized structural equation modelling. Int J Ment Health Syst 2018;12:62.

32 Dadi AF, Dachew BA, Kisi T, et al. Anxiety and associated factors among prisoners in North West of Amhara regional state, Ethiopia. BMC Psychiatry 2016;16:83.

33 Hakim A, Tak H, Nagar S, et al. Assessment of prevalence of depression and anxiety and factors associated with them in undergraduate medical students of Dr. S. N. medical College, Jodhpur. Int J Community Med Public Health 2017;4:3267.

34 Collier KM, Weiss B, Pollack A, et al. Explanatory variables for women's increased risk for mental health problems in Vietnam. Soc Psychiatry Psychiatr Epidemiol 2020;55:359-69.

35 Pham Tien N, Pham Thanh T, Nguyen Hanh D, et al. Utilization of mental health services among university students in Vietnam. Int $J$ Ment Health 2020;58:1-23.

36 Pollack AA, Weiss B, Trung LT. Mental health, life functioning and risk factors among people exposed to frequent natural disasters and chronic poverty in Vietnam. BJPsych Open 2016;2:221-32.

37 Carroll HA, Hook K, Perez OFR, et al. Establishing reliability and validity for mental health screening instruments in resourceconstrained settings: systematic review of the PHQ-9 and key recommendations. Psychiatry Res 2020;291:113236.

38 Zhong Q-Y, Gelaye B, Rondon MB, et al. Using the patient health questionnaire (PHQ-9) and the Edinburgh postnatal depression scale (EPDS) to assess suicidal ideation among pregnant women in Lima, Peru. Arch Womens Ment Health 2015;18:783-92.

39 Gelaye B, Williams MA, Lemma S, et al. Validity of the patient health Questionnaire-9 for depression screening and diagnosis in East Africa. Psychiatry Res 2013;210:653-61.

40 Woldetensay YK, Belachew T, Tesfaye M, et al. Validation of the patient health questionnaire (PHQ-9) as a screening tool for depression in pregnant women: Afaan Oromo version. PLoS One 2018;13:e0191782

41 Nguyen TQ, Bandeen-Roche K, Bass JK, et al. A tool for sexual minority mental health research: the patient health questionnaire (PHQ-9) as a depressive symptom severity measure for sexual minority women in Viet Nam. J Gay Lesbian Ment Health 2016;20:173-91.

42 Mokona H, Yohannes K, Ayano G. Youth unemployment and mental health: prevalence and associated factors of depression among unemployed young adults in Gedeo zone, Southern Ethiopia. Int J Ment Health Syst 2020;14:61. 
43 Molla GL, Sebhat HM, Hussen ZN, et al. Depression among Ethiopian adults: cross-sectional study. Psychiatry J 2016;2016:1-5.

44 Gupta R, Taneja N, Anand T, et al. Internet addiction, sleep quality and depressive symptoms amongst medical students in Delhi, India. Community Ment Health J 2021;57:771-6.

45 Roberts T, Shidhaye R, Patel V, et al. Health care use and treatment-seeking for depression symptoms in rural India: an exploratory cross-sectional analysis. BMC Health Serv Res 2020;20:287.

46 Hernández-Vásquez A, Rojas-Roque C, Vargas-Fernández R, et al. Dynamics of depressive symptoms and within-country migration among Peruvian women. Rural Remote Health 2020;20:5692.

47 Hernández-Vásquez A, Vargas-Fernández R, Bendezu-Quispe G, et al. Depression in the Peruvian population and its associated factors: analysis of a national health survey. J Affect Disord 2020;273:291-7.

48 Spitzer RL, Kroenke K, Williams JBW, et al. A brief measure for assessing generalized anxiety disorder: the GAD-7. Arch Intern Med 2006;166:1092-7.

49 Kroenke K, Strine TW, Spitzer RL, et al. The PHQ-8 as a measure of current depression in the general population. J Affect Disord 2009;114:163-73.

50 Cronbach LJ. Coefficient alpha and the internal structure of tests. Psychometrika 1951;16:297-334.

51 Nunnally J, Bernstein I. Psychometric theory. 3rd edn. New York: McGraw-Hill, 1994.

52 Briggs SR, Cheek JM. The role of factor analysis in the development and evaluation of personality scales. J Pers 1986;54:106-48.

53 Clark LA, Watson D. Constructing validity: basic issues in objective scale development. Psychol Assess 1995;7:309-19.

54 Cantril H. The pattern of human concerns. 1965. New Brunswick, NJ: Rutgers University Press, 1965.

55 Briones K. 'How Many Rooms Are There in Your House?'Constructing the Young Lives Wealth Index. 43, 2017. https://www.younglives.org.uk/sites/www.younglives.org.uk/files/YLTN43 0.pdf

56 Marsh HW. Self description questionnaire (SDQ) II: a theoretical and empirical basis for the measurement of multiple dimensions of adolescent self-concept. San Antonio, TX: Psychological Corporation, 1990.

57 Marsh HW. The self description questionnaire (SDQ): a theoretical and empirical basis for the measurement of multiple dimensions of preadolescent self-concept: a test manual and research monograph. San Antonio, TX: Psychological Corporation, 1988.
58 Amsalem D, Dixon LB, Neria Y. The coronavirus disease 2019 (COVID-19) outbreak and mental health: current risks and recommended actions. JAMA Psychiatry 2021;78:9-10.

59 Ritchie H, Ortiz-Ospina E, Beltekian D. Coronavirus pandemic data explorer. In: OurWorldInData.org, ed. Oxford Martin School, University of Oxford, 2020.

60 McLean CP, Asnaani A, Litz BT, et al. Gender differences in anxiety disorders: prevalence, course of illness, comorbidity and burden of illness. J Psychiatr Res 2011;45:1027-35.

61 Salk RH, Hyde JS, Abramson LY. Gender differences in depression in representative national samples: meta-analyses of diagnoses and symptoms. Psychol Bull 2017;143:783-822.

62 Dachew BA, Bifftu BB, Tiruneh BT, et al. Prevalence of mental distress and associated factors among university students in Ethiopia: a meta-analysis. J Ment Health 2019:1-8.

63 Hailemariam S, Tessema F, Asefa M, et al. The prevalence of depression and associated factors in Ethiopia: findings from the National health survey. Int J Ment Health Syst 2012;6:23.

64 Nguyen A. Cultural and social attitudes towards mental illness in Ho Chi Minh City. Vietnam: Seattle University Research Journal, 2003: 2. 27-31.

65 Reta Y, Tesfaye M, Girma E, et al. Public stigma against people with mental illness in Jimma town, Southwest Ethiopia. PLoS One 2016;11:e0163103.

66 Arriola-Vigo JA, Stovall JG, Moon TD, et al. Perceptions of community involvement in the Peruvian mental health reform process among clinicians and Policy-Makers: a qualitative study. Int $J$ Health Policy Manag 2019;8:711-22.

67 Gaiha SM, Taylor Salisbury T, Koschorke M, et al. Stigma associated with mental health problems among young people in India: a systematic review of magnitude, manifestations and recommendations. BMC Psychiatry 2020;20:538.

68 Kane JC, Elafros MA, Murray SM, et al. A scoping review of healthrelated stigma outcomes for high-burden diseases in low- and middle-income countries. BMC Med 2019;17:17.

69 Mascayano F, Armijo JE, Yang LH. Addressing stigma relating to mental illness in low- and middle-income countries. Front Psychiatry 2015;6:38.

70 Bauer A, Garman E, McDaid D, et al. Integrating youth mental health into cash transfer programmes in response to the COVID-19 crisis in low-income and middle-income countries. Lancet Psychiatry 2021;8:340-6.

71 Dong E, Du H, Gardner L. An interactive web-based dashboard to track COVID-19 in real time. Lancet Infect Dis 2020;20:533-4. 